\title{
Ectopic ACTH syndrome as a presenting symptom of bronchogenic carcinoma
}

\author{
Safwaan Adam ${ }^{1}$, Ronald Kato², Sarah Rose ${ }^{1}$, Harni Bharaj ${ }^{1}$, Ambar Basu1 \\ 1 Royal Bolton Hospital; 2 Blackpool Victoria Hospital
}

\section{Introduction}

Ectopic ACTH Syndrome (EAS) is associated with small cell carcinoma of the lung. It is reported as a rare condition and may not present with classical clinical findings of Cushing's Syndrome. Here we report 3 cases of undiagnosed bronchogenic carcinoma who presented with EAS within a period of 12 months.

\section{Cases}

\section{Case 1}

67 year old lady, smoker, presented with severe proximal myopathy of 4 week duration. Clinically she appeared cushingoid with newly diagnosed Type 2 Diabetes. Lab tests revealed a potassium of $2.3 \mathrm{mmol} / /$ and bicarbonate of $37 \mathrm{mmol} / \mathrm{l}$. CXR showed abnormal shadow at left hilum. 9am cortisol-1406, ACTH-80(normal-0-40). CT scan of thorax/abdomen/pelvis revealed a large left hilar mass, infiltrating left main bronchus, There were multiple hepatic and bilateral adrenal metastatic lesions.

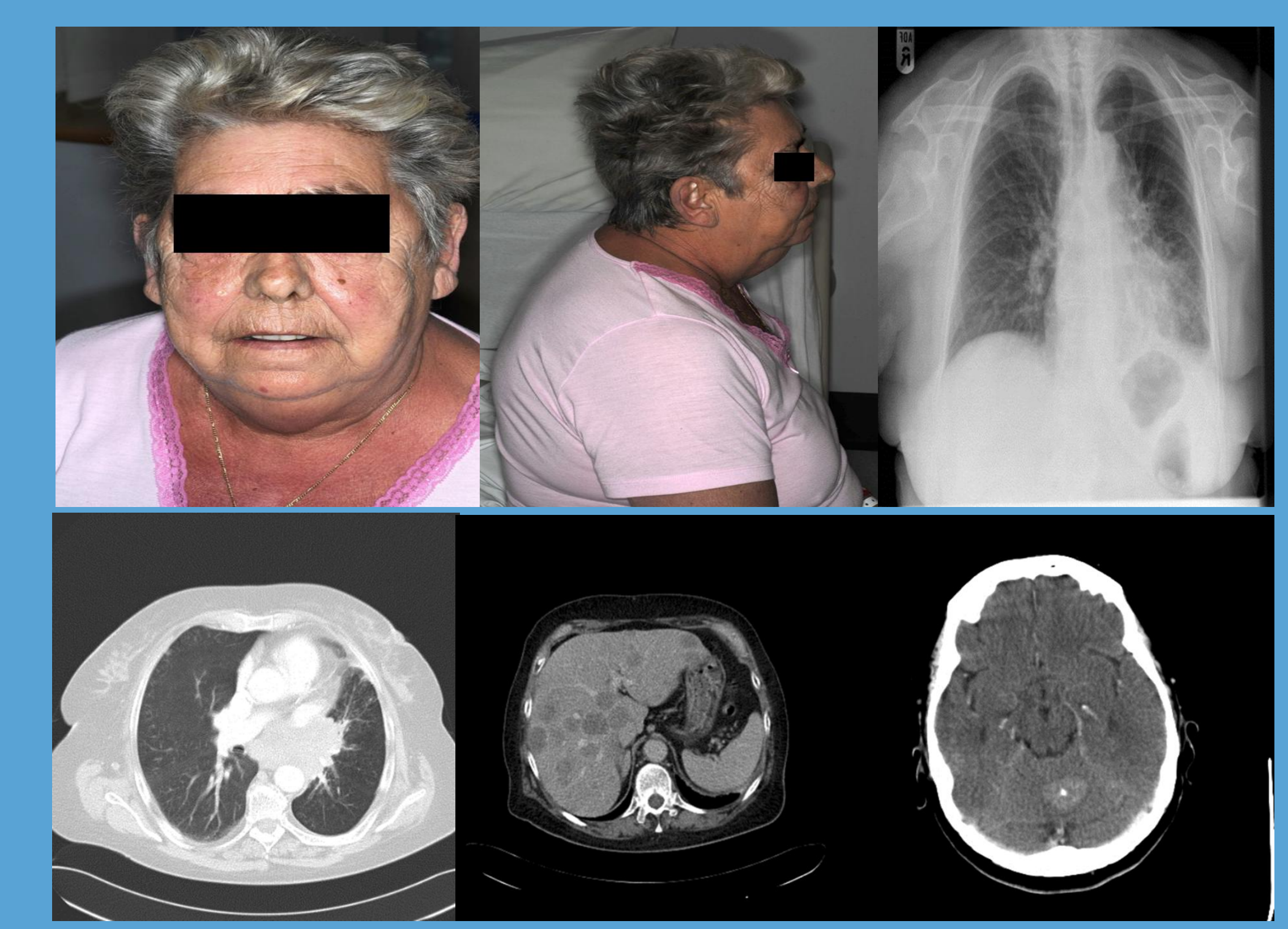

\section{Case 2}

A 53 year old female smoker presented with shortness of breath and weight loss. Her blood pressure had become uncontrolled despite being on several antihypertensives and she had newly diagnosed diabetes. Clinically, she was cushingoid with severe proximal myopathy. Lab tests revealed her potassium was $2.5 \mathrm{mmol} / \mathrm{l}$, bicarbonate 35 $\mathrm{mmol} / \mathrm{l}$ and glucose $30 \mathrm{mmol} / \mathrm{l}$. Chest radiograph showed right lower lobe consolidation. An early morning cortisol >1600//L (normal range 450$700 \mathrm{nmol} / \mathrm{L}$ ). Her serum ACTH was 96ng/L (normal range $<80 \mathrm{ng} / \mathrm{L}$ ) even in the presence of a high cortisol. Bronchoscopy findings were a bronchogenic carcinoma with the histology proving small cell lung carcinoma(SCLC).
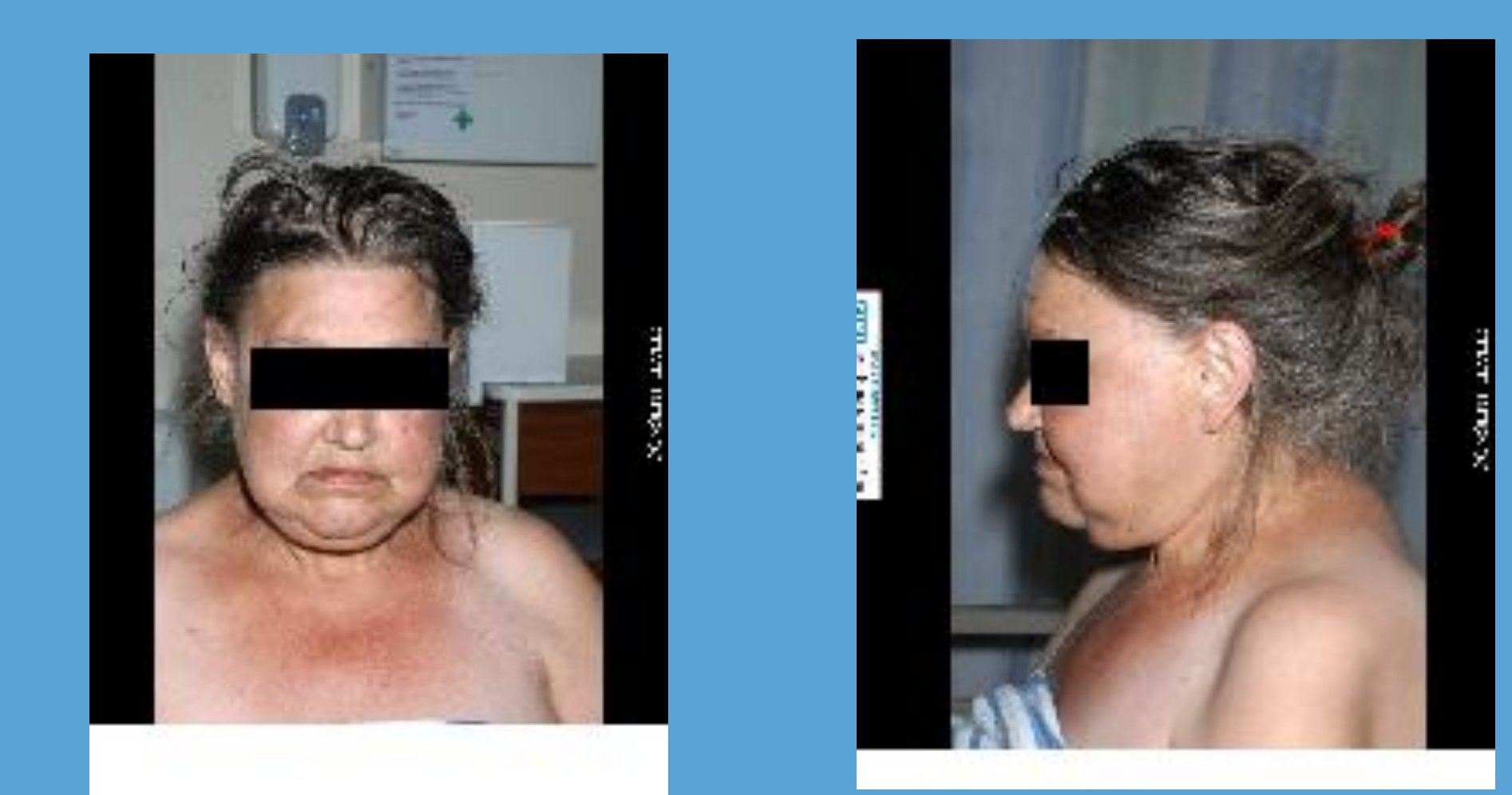

Case 3

A 70 yr. old male, non-smoker, presented with shortness of breath for 6 months. He had dysphagia, weight loss and hoarseness of voice. Lab tests revealed a potassium of $2.5 \mathrm{mmol} / \mathrm{L}$, with normal sodium, urea and creatinine. Serum bicarbonate was $35 \mathrm{mmol} / \mathrm{l}$. Chest radiograph showed a left hilar mass and left basal consolidation. His 9am cortisol sample was 1595nmol/L (normal450-700nmol/L). CT staging showed multiple masses within the mediastinum and left hilum. There were multiple liver metastasis. Bronchoscopy revealed tumours in the left upper lobe. Histology proved small cell lung carcinoma.

\section{Discussion}

The association of Cushing's syndrome with small cell lung carcinoma (SCLC) was first described in 19281. It was subsequently discovered that various tumours, mostly those of neuroendocrine origin, are able to secrete ACTH, giving rise to the term "Ectopic ACTH Syndrome" $(\mathrm{EAS})^{2}$

SCLC is responsible for $27 \%$ of all cases of $\mathrm{EAS}^{3}$, and it is estimated that nearly $5 \%$ of all patients with SCLC have EAS ${ }^{4}$. If undiagnosed, EAS can lead to significant additional comorbidity6.

There are no features pathognomonic of this disease ${ }^{5}$. An overt malignancy such as SCLC often means that due to the rapid clinical course, features of metastatic disease predominate over those of Cushing's syndrome. The development of "classic" cushingoid features is dependent of the length of time of exposure to the body of circulating glucocorticoids ${ }^{7}$. Therefore, in EAS symptoms of muscle wasting and weakness, and clinical features such as hypertension and hypokalaemia may be the predominant features ${ }^{8}$.

A high index of clinical suspicion is necessary to consider the diagnosis. Initial investigations should establish whether the patient has hypercortisolism.

Investigation Pathway for EAS

\begin{tabular}{c}
\hline Clinical suspicion? \\
Urinary free cortisol/Salivary cortisol \\
Low dose Dexamethasone Suppression test \\
$\downarrow$ \\
Plasma ACTH levels \\
\hline
\end{tabular}

Several treatments have been proposed for EAS, the most important of which, is eradication of the cancer either surgically or through chemotherapy. However in many cases this is not possible, and pharmacological therapy to alleviate symptoms is instituted. Adrenal enzyme inhibitors such as Ketoconazole, Metyrapone and Trilostane have all been used ${ }^{10}$ for symptomatic relief.

\section{Key Learning Points}

- The cases discussed had different clinical presentation with varying findings

Patients with possible lung cancer with hypokalaemia without an obvious reason should raise the possibility of the presence of ectopic ACTH secreting bronchial carcinoma.

A high index of suspicion is needed to start the investigation pathway

- In terms of investigation, tests should be done to establish hypercortisolism with measurement of ACTH

- Management should be determined by the stage of the underlying disease but symptom control with medications such as metyrapone should be considered to improve the quality of life for these patients

\section{References}

1. Brown WF, Oxf BM. A case of pluriglandular syndrome; diabetes of bearded women. Lancet 1928; 2 10221023

2. Isodori Am, Lenza A. Ectopic ACTH syndrome Arquivos Brasileros de Endocrinology and Metabologia. 51(8) 2007

3. Beuschlein F, Hamner GD. Ectopic poropiomelanocortin syndrome. Endocrinol metab Clinic North Am 2002 Mar (31) 191 234

4. Shepherd FA, Lasky J, Evans WK, Goss PE, Johansen E, Khamsi F. Cushing's syndrome associated with ectopic corticotrophin production and small cel ung cancer. J Clin Oncol 1992 Jane 10(1) 2127

5. Nieman LK, Biller BM, Findling JW et al. The diagnosis of Cushing's syndrome: An endocrine society clinical practice guideline. J Endocrinol metab 2008 93:1526-1540

6. Orth DN. Cushing's syndrome. N Engl J medicine 1995 332: 791-803

7. Nieman LK. Clinical manifestations of Cushing's syndrome. Up to Date www. Uptodate.com. Accessed 20/10/2010

8. Ma Y, Aitelli C, Dobson R, Konduri K. Ectopic adrenocortocotrophic syndrome: a diagnostic challenge and review of the literature. Baylor University Medical center proceedings 2010 Oct 23(4): 426-428 9. Newell-Price J, Trainer P, Besser M, Grossman A. The diagnosis and differential diagnosis of Cushing's Syndrome and Pseudo-Cushing's states. Endocrine reviews 1998 19(5) 647-672

10.Niemann LK. Overview of the treatment of Cushing's syndrome. Up to date. Accessed 09/01/2013

Presenter:

Safwaan Adam, ST4 Diabetes/Endocrinology, safadam@yahoo.com 